ISSN: 2162-3104 Print/ ISSN: 2166-3750 Online

Volume 8, Issue 2 (2018), pp. 821-842

(C) Journal of International Students

http://jistudents.org/

doi: $10.5281 /$ zenodo. 1250383

\title{
Cross-cultural Adaptation of International College Students in the United States
}

\author{
Yikang Wang \\ Ting Li \\ Amity Noltemeyer \\ Aimin Wang \\ Jinghua Zhang \\ Kevin Shaw \\ Miami University, Oxford, Ohio, USA
}

\begin{abstract}
The number of international students attending U.S. colleges and universities has increased considerably over the past decade, and the adaptation of these students is an important concern in cross-cultural research. Using survey data collected from a sample of 169 international students attending a U.S. university, this study examines the temporal patterns of students' psychological and socio-cultural adaptation. The results suggest a two-phase U-curved process of psychological adaptation, with the most obvious culture shock occurring during a student's first nine to 24 months of residence. Socio-cultural adaptation is found to increase steadily over time, without significant retreat. Interpretations, implications, and limitations of the findings are provided.
\end{abstract}

Keywords: International students, Psychological adaptation, Socio-cultural adaptation, U-curve 
Concurrent with economic and cultural globalization, study abroad opportunities have become increasingly appealing to college students seeking educational opportunities. Among the possible study abroad destinations, the United States continues to be the first choice. In fact, the United States hosts the largest population of international students, and the number has been consistently rising (Institute of International Education, 2016). For example, there were $1,043,839$ international students enrolled in American colleges and universities during the 2015-2016 school year, a $7.1 \%$ increase from the year prior (Institute of International Education, 2016). This study considers the cross-cultural adaptation of international college students in the United States by examining two subtypes of adaptation: psychological adaptation and socio-cultural adaptation.

\section{LITERATURE REVIEW}

\section{Cross-Cultural Adaptation}

The term adaptation was originally conceptualized within evolutionary biology, referring to a group's survival in a new physical environment (Harrison, 1993). However, as the definition expanded to social and cultural spheres, it was interpreted in the context of developing behavioral and psychological adaptive mechanisms (Harrison, 1993).

International students in the United States often experience adaptation difficulties upon relocating to different cultural and language surroundings. Culture shock, challenges, and miscommunications can occur when they immerse themselves into American social, cultural and academic life. Since the twentieth century, cross-cultural adaptation has become important when studying "a large and continuous influx of immigrants and sojourners" (Kim, 2000, p. 11). Kim (2000) conceptualized cross-cultural adaptation as a systematic and comprehensive process where immigrants change from being cultural outsiders to increasingly active and effective cultural insiders. Individuals who feel unfamiliar or uncomfortable with the new surroundings may be limited to potentially maladaptive behaviors used in their native settings.

Defined as a multifaceted process (Moghaddam, Taylor, \& Wright, 1993), most cross-cultural adaptation can be categorized into theoretical models that fall into one of two categories: macro-level and micro-level perspectives (Kim, 2000). Macro-level approaches view adaptation as a group phenomenon, focusing on a group's acculturation in the host culture's 
values or life patterns. For example, Berry (1990) proposed the interactive pattern of two dimensions of acculturation: 1) the extent to which the original culture is valued and maintained, and 2) the extent to which the host culture is accepted. However, Berry's model may be insufficient to comprehensively understand acculturation because certain personal and situational factors are not taken into account. Other studies (e.g., Ward \& Searle, 1991) have been conducted from the micro-level perspective, with the primary emphasis on interpersonal and intrapersonal experiences of newcomers.

Studies in cross-cultural adaptation can also be categorized based on features of the newcomers. Long-term adaptation is relevant to immigrants and refugees, whereas short-term adaptation is relevant to "travelers and temporary sojourners" (Kim, 2000, p. 39). The pattern of adaptation for these groups can vary (Kim, 2000). For instance, short-term sojourners stay in the host country temporarily (generally from six months to five years), relocate voluntarily, and have plans to return home. These characteristics distinguish them from both immigrants who are more involved in the host community and travelers who are less committed to the new culture (Kim, 2000). Research on the acculturation attitudes of 219 international students (including both immigrants and sojourners) at a major Israeli university revealed that sojourning students have less positive attitudes towards integration and assimilation into the host country than do immigrant students (Tatar \& Horenczyk, 2000).

Among transient populations, international students are considered particularly vulnerable when learning to adjust in their new environment. International students are confronted with challenges (Furukawa, 1997), such as language and academic difficulties (Li et al., 2017; Yan \& Berliner, 2009), financial pressures (Poyrazli \& Grahame, 2007), and limited social support (O'Reilly, Ryan, \& Hickey, 2010; Kim \& Abreu, 2001). Studying foreign students in an Irish university, O'Reilly et al. (2010) found that these students deal with a large number of socio-cultural difficulties, such as using the native language, using the Irish transportation system, or understanding Irish politics. Regarding the psychological state of international students, they may experience anxiety or depression caused by culture shock, stress from the high expectations concerning academic performance, a sense of loss precipitated by their changed social and economic status, and feelings of discrimination or isolation (Oropeza, Fitzgibbon, \& Baron, 1991). Furthermore, these crises may persist longer than expected. For example, in 
a study of 199 Japanese adolescents returning from a one-year study abroad program, students experienced substantial emotional stress even six months after returning home (Furukawa, 1997). Given international students' unique experiences, their cross-cultural adaptation should be studied independent of other groups of transients.

Cross-cultural adaptation can be further categorized into two subtypes: psychological and socio-cultural. Psychological adaption refers to "feelings of well-being or satisfaction during cross-cultural transitions" (Ward, Bochner, \& Furnham, 2001, p.42). More specifically, Moghaddam et al. (1993) referred to it as the maintenance of good mental health, and "positive mood-state, feelings of contentment, and acceptance of one's new environment" (p. 137). In other words, psychological adaptation involves perceiving life as satisfactory, having a positive purpose in life, or exhibiting a high level of self-acceptance and autonomy (Klemens \& Bikos, 2009). Studies have identified factors that predict psychological adjustment in international students. For example, Kim and Kim (2016) found that (a) communication competence in the host environment, (b) interpersonal relationships in the host environment, and (c) the degree of similarity between the student's ethnicity and that of the host environment were positively associated with psychological health in European and Asian international college students studying in the United States.

Socio-cultural adaptation is the ability to fit in to the new culture (Ward et al., 2001). The social skills and behaviors successfully acquired in daily cultural learning can represent a desired level of socio-cultural adaptation, which further involves two elements: the development of "positive interpersonal relations with members of the host culture" and "some level of effectiveness in carrying out the necessary tasks at hand" (Moghaddam et al., 1993, p. 138). To achieve these goals, both verbal and non-verbal interactions are required. Linguistic comprehension is needed for the former, and an understanding of non-verbal signals, such as etiquette, bodily contact, and gestures, is necessary for the latter (Ward et al., 2001). Bierwiaczonek and Waldzus (2016) identified five antecedents of sociocultural adaptation within in existing literature: cultural distance (e.g., degree to which the host culture differs from one's own culture), social interaction (e.g., quantity and frequency of contact), social resources (e.g., social support from peers), social stressors (e.g., perceived discrimination), and family-related variables (e.g., marital status). 


\section{U-curve Adaptation}

Cultural newcomers are likely to experience fluctuations in adaptation over time. In this sense, the length of residence serves as a significant predictor of adaptation, especially in the socio-cultural domain (Ward et al., 2001). The temporal variation was originally demonstrated to be a linear model through which adaptation sloped upward. Inspired by this preliminary model, researchers such as Oberg (1960) and Lysgaard (1955) constructed curvilinear models to provide a more precise picture of adaptation. For example, it has been claimed that adaptation may be predicted in a model that "improves rapidly in the earliest stages of transition, reaches a plateau, and then appears to stabilize" (Ward et al., 2001, p.42). The more widely adopted models are the U-curve model (Lysgaard, 1955; Oberg, 1960) and W-curve model (Gullahorn \& Gullahorn, 1963; Zeller \& Mosier, 1993). Given that the W-curve model considers re-entry into the home country (Zeller \& Mosier, 1993), an issue outside of the scope of this study, this study focuses on the U-curve model.

Originally developed by Lysgaard (1955) in a study of Norwegian scholars in the United States, the U-curve portrays the lowest point of adaptation, called Crisis. Refined by Oberg (1960), a similar model with specific stages of adaptation over time was developed. According to Oberg, cultural adaptation starts with a Honeymoon Stage, during which sojourners tend to feel excited about new experiences, such as making new friends or observing the new culture. It is followed by the Culture Shock Stage, consistent with the Crisis idea mentioned above. Sojourners in this stage are highly likely to suffer from anxiety and conflicts. For example, they might feel lonely, isolated, helpless, or find it hard to use appropriate behaviors to abide by the host culture's conventions. The next stage is the Recovery Stage, during which cultural differences are accepted and adapted to. The stability of mood and positive attitudes comes along on a day-to-day basis. Finally, in the Adaptation Stage, people are able to function fairly well and reach a higher level of adaptation.

The U-curve model provides a strong heuristic approach to understanding and evaluating the adaptation pathway. However, it is worth mentioning that this U-shaped process is by no means universal to every individual in every situation (Moghaddam et al., 1993). Due to certain life events, such as facing the pressure of graduation or searching for a career, a poor adaptive stage might re-occur. In addition, the length and degree of the stages could differ between individuals (Berry, 2005). 
Other researchers have proposed similar models to the U-curve. However, most of these models lack a time frame for each stage (Brown \& Holloway, 2008). One possible reason for this could be the difficulty in determining a general pattern, given that "in one context, a person may suffer the lowest point on the curve after only one or two months; in another environment, this point may be reached after many months or even years" (Moghaddam et al., 1993, p. 144). Lysgaard (1955) claimed that the poorest adaptation was most likely revealed during six to 18 months of arrival. By contrast, Brown and Holloway (2008) found that the most overwhelming period for the international postgraduate students at a university in England was at the beginning of the stay. In the initial stage, negative symptoms caused by culture shock were most noticeable. In research conducted by Ward et al. (1998), both the socio-cultural and psychological adaptation of 35 Japanese students studying in New Zealand were examined. The results showed that they experienced severe social difficulties early in their entry to the new culture, with these difficulties decreasing between entry and four months and leveling off at six and 12 months.

\section{Rationale and Purpose}

The present study examined how the psychological and sociocultural adaptation of international college students in the United States varied over time. Two domains of adaptation were examined separately: 1) psychological adaptation was measured by participants' perceived life satisfaction; 2) socio-cultural adaptation was measured by self-reported competency of socio-cultural skills. It was hypothesized that the pattern of both psychological and socio-cultural adaptation would follow the U-shaped model over time of residence. In particular, within five to eight months of arrival, students would encounter more adaptation difficulties than those in residence less than five months or more than eight months.

\section{RESEARCH METHOD}

\section{Participants}

This research was conducted with a population of international students attending a coeducational public research university in midwestern United States. In order to obtain a broad and diverse sample, we recruited both undergraduate and graduate students of any age, gender, length of residence, nationality, first language, and major. One hundred sixty-nine 
students participated and provided valid responses to the questionnaires. Table 1 summarizes key demographic information about the participants. Ninety-six female students accounted for $56.8 \%$ of the sample. Their ages ranged between 18 and 34 years old $(\mathrm{M}=22.82, \mathrm{SD}=3.05)$. Ninety-seven or $57.4 \%$ identified as undergraduate students, with 37 freshmen, 24 sophomores, 17 juniors, and 19 seniors. Seventy-two graduate students accounted for $42.6 \%$ of the sample.

With respect to the students' length of residence, 91 had been in the United States for less than one year, 35 for one to two years, 19 for two to three years, 12 for three to four years, and 12 for more than four years. Among those with a length of residence of less than one year, 46 had been in the United States for one to four months, 24 for five to eight months, and 21 for nine to 12 months.

Table 1. Demographic Information by Number and Percentage of Gender, Length of Residence, and Geographical Areas.

\begin{tabular}{llll}
\hline & & Number & Percentage (\%) \\
\hline Gender & Female & 96 & 56.8 \\
Length of & Male & 73 & 43.2 \\
Residence & $1-4$ months & 46 & 27.2 \\
& 5-8 months & 24 & 14.2 \\
& $9-12$ months & 21 & 12.4 \\
& 13-24 months & 35 & 20.7 \\
& 25-36 months & 19 & 11.2 \\
Geographical & 37-48 months & 12 & 7.1 \\
Areas & 49+ months & 12 & 7.1 \\
& Americas & 5 & 3.0 \\
& Europe & 9 & 5.3 \\
& Africa & 5 & 3.0 \\
& East Asia & 110 & 65.1 \\
& South East Asia & 8 & 4.7 \\
& South Central Asia & 28 & 16.6 \\
Valid Total & Western & 4 & 2.4 \\
\hline
\end{tabular}


In addition, participants were from 31 different countries, within seven broader geographical areas. The geographic distribution of the participants roughly mirrored the international student enrollment university-wide; for example, East Asian countries were the most heavily represented. Thirty-two different languages were reported as the first language, with Chinese accounting for the highest percentage. Thirty-two participants or $19.5 \%$ of the total sample spoke English as an official language in their country.

\section{Instruments}

The researchers used three surveys in this study. First, a demographic survey designed by the first author was used to collect information on participants' gender, date of birth, student status, nationality, native language, and length of residence (in months). Additionally, two published scales - the Satisfaction with Life Scale (SWLS; Diener, Emmons, Larsen, \& Griffin, 1985) and the revised Sociocultural Adaptation Scale (SCAS-R; Wilson \& Ward, 2010) - were used to assess life satisfaction and socio-cultural adaptation.

\section{Life Satisfaction}

The Satisfaction with Life Scale (SWLS), developed by Diener et al. (1985), was used to assess participants' psychological adaptation. The SWLS was originally designed to detect the respondent's overall life satisfaction, indicated by one's own perceived and conscious judgment of satisfaction with life (Pavot \& Diener, 1993). The scale consists of five statements (e.g., "In most ways my life is close to my ideal") that are responded to using a 7-point Likert response format. Participants were asked to indicate the degree of agreement with each statement that reflected their global judgment of life satisfaction and well-being, with 7 representing "strongly agree" and 1 representing "strongly disagree." The SWLS has acceptable construct validity to assess one's global life satisfaction (Diener et al., 1985). It has been translated into different languages, and the English version was used in the current study. The correlation coefficient of the testretest reliability was .82 , and the coefficient alpha was .87 (Diener et al., 1985).

To interpret the scores, cutoffs were applied based on the summed aggregate score recommended by the test creators (Diener et al., 1985). Specifically, participants who scored in the range of 30-35 were considered 
to be very highly satisfied, enjoy their lives and believe that their lives were going very well. Those who scored in the range of 25-29 felt their lives were going well, and participants who scored in the range of 20-24 were usually satisfied but may have needed improvement in their lives. Participants who fell in the range of 15-19 were evaluated as slightly below average in life satisfaction and had small but significant problems in their lives. Those who scored in the range of 10-14 might be dissatisfied with some notable facet of their lives. Those who scored in the range of five to nine were considered to be extremely dissatisfied and unhappy with their lives.

\section{Socio-Cultural Adaptation}

To measure participants' socio-cultural adaptation, the revised version of the Sociocultural Adaptation Scale (SCAS-R; Wilson \& Ward, 2010) was used. The original Socio-cultural Adaptation Scale (Searle \& Ward, 1990) contains 16 items based on an earlier scale developed by Trower, Bryant and Argyle (1978). The revision was made by Wilson and Ward in 2010, retaining the 5-point Likert format (1- Not at all competent, 5- Extremely competent), but extending the total items to 21. Responses reflect the degree to which participants believe they are competent in gaining specific new skills and behaviors in a new culture (e.g. "interacting at social events" or "building and maintaining relationships"). Results are computed into average scores. The overall reliability, Cronbach alpha calculated with the current sample, is .92.

\section{Procedure}

This study's procedures were approved by the Institutional Review Board at the participating university. Questionnaires written in English were completed voluntarily and anonymously. Both paper and electronic versions of the questionnaire were made available. The paper version was distributed at events held for international students, and the electronic version was distributed through email listservs of the Office of International Education and some student organizations of the university where the research was conducted. It took approximately 10 minutes to finish all the items. Two hundred and eighty-four students opened the link that was sent to them, and 88 of them finished the online questionnaire. Sixty-nine students were given the paper version of the questionnaire and 54 finished and submitted it. In total, 169 responses were considered valid. 


\section{RESULTS}

\section{Descriptive Analyses}

To explore the effect of international students' length of residence in the United States on their life satisfaction and socio-cultural skills, descriptive analyses were conducted to gain a general idea of how these two dependent variables changed over time. The length of residence was classified into seven categories for data collection. These categories were one to four months, five to eight months, nine to 12 months, 13-24 months, 25-36 months, 37-48 months, and longer than 49 months, roughly based on the semesters or school years that the students have been enrolled.

Table 2. Descriptive Statistics of Life Satisfaction and Socio-cultural Skills by Months of Residence.

\begin{tabular}{llll}
\hline & $\begin{array}{l}\text { Life } \\
\text { Satisfaction }\end{array}$ & $\begin{array}{l}\text { M (SD) } \\
\text { Socio-cultural } \\
\text { Skills }\end{array}$ & $N$ \\
\hline 1-4 Months & $23.91(4.91)$ & $57.52(12.74)$ & 46 \\
5-8 Months & $24.42(3.07)$ & $60.04(12.35)$ & 24 \\
9-12 Months & $22.29(3.11)$ & $61.38(11.04)$ & 21 \\
13-24 Months & $22.71(3.25)$ & $61.00(13.23)$ & 35 \\
25-36 Months & $24.32(2.77)$ & $63.79(15.60)$ & 19 \\
37-48 Months & $24.00(3.22)$ & $64.25(11.60)$ & 12 \\
49+ Months & $25.58(2.75)$ & $69.33(12.08)$ & 12 \\
Total & $\mathbf{2 3 . 7 0 ( 3 . 7 2 )}$ & $\mathbf{6 1 . 1 0}(\mathbf{1 3 . 0 0})$ & $\mathbf{1 6 9}$ \\
\hline
\end{tabular}

Table 2 shows the descriptive statistics, including the sample size, means, and standard deviations for each residence length category. Figure 1 illustrates the profile plots of the changes of life satisfaction and sociocultural skills over time. Figure 2 shows the relationship between length of residence and life satisfaction, with both a pre-assumed linear regression line and modified regression line. The linear line fit poorly with the data whereas the smoothened line demonstrated a potential U-curved shape. Curve estimation was then performed with length of residence as the independent variable and life satisfaction as a dependent variable. 


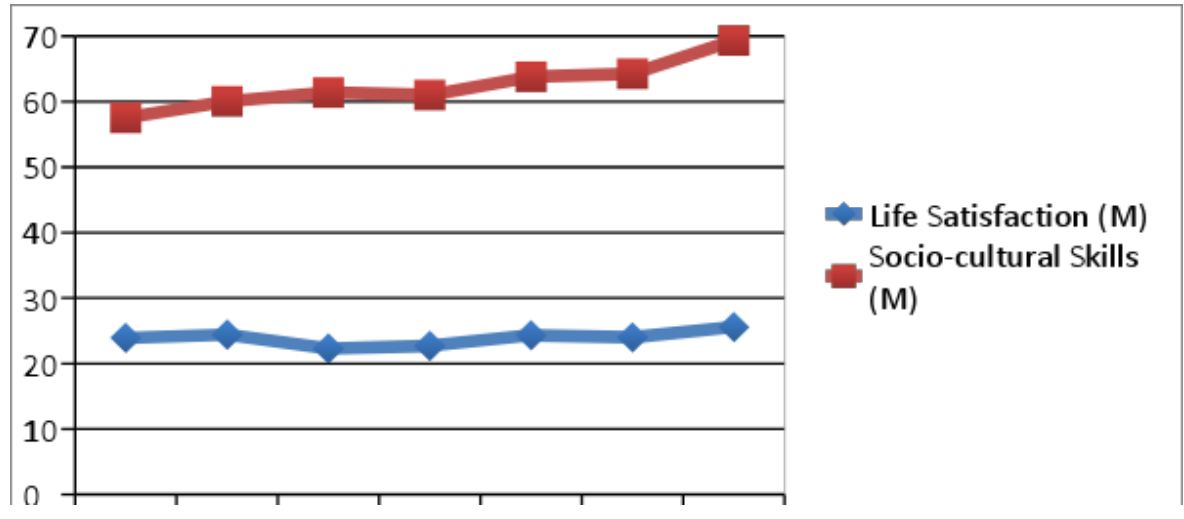

Figure 1. Profile Plots of the Changes of Life Satisfaction and SocioCultural Skills Over 7 Periods of Time

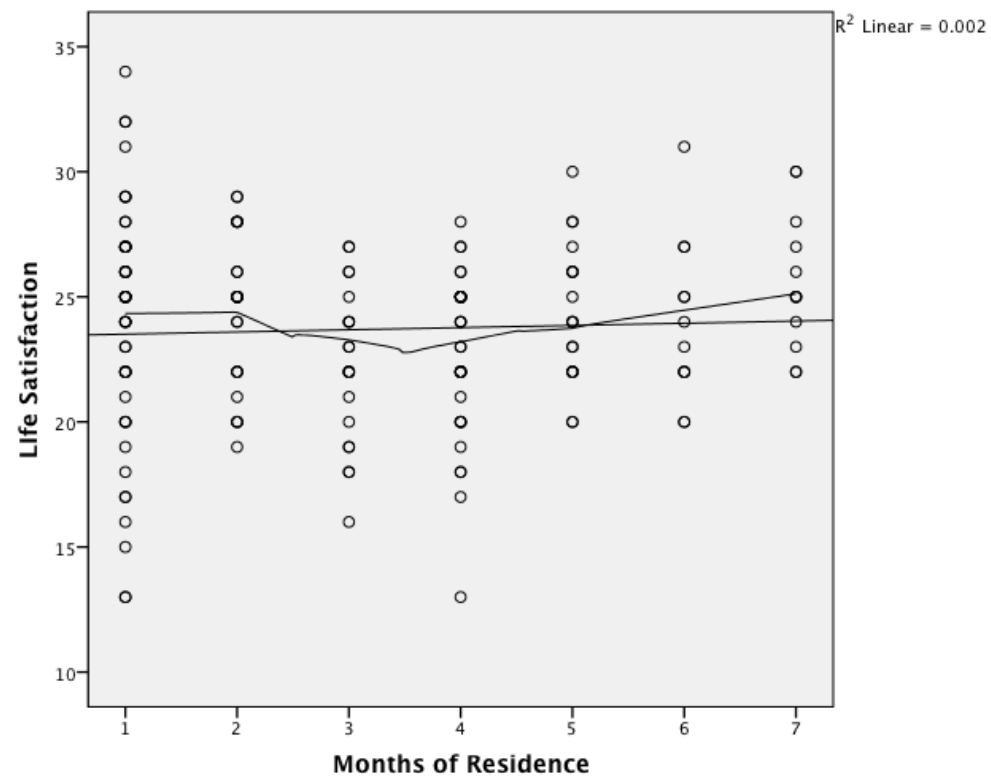

Figure 2. Examination of Linearity between Length of Residence and Life Satisfaction 
Table 3 shows the model summary and parameter estimates of the regression equation. Aligned with the trend demonstrated by the scatter plot in Figure 1, only the quadratic equation model of the data is significant, with $\mathrm{F}(2,166)=3.104, \mathrm{p}<.05$. The equation of this quadratic model is life satisfaction $=25.269-1.351$ (length of residence) +0.199 (length of residence)2. Figure 3 shows the U-curved nonlinear relationship between length of residence and life satisfaction, with a bend point appearing appropriately between 13 and 24 months of students' arrival to the United States. The practical interpretation of this result is that the second year of staying in the United States (13-24 months) was crucial for most international students, as their initially decreased trend of life satisfaction started to turn upwards. Furthermore, after staying in the United States for longer than 37 months, their level of life satisfaction would restore gradually to the same level as when they first arrived in the country.

Table 3. Model Summary and Parameter Estimates for the Regression Relationship between Length of Residence and Life Satisfaction.

\begin{tabular}{llllllllll}
\hline \multirow{2}{*}{ Equation } & \multicolumn{3}{l}{ Model Summary } & \multicolumn{6}{c}{ Parameter Estimates } \\
\cline { 2 - 10 } & $R^{2}$ & $F$ & $d f 1$ & $d f$ & Sig. & Constant & $b 1$ & $b 2$ & $b 3$ \\
\hline Linear & .002 & .33 & 1 & 167 & .564 & 23.42 & .09 & & \\
Quadratic & .036 & 3.10 & 2 & 166 & .047 & 25.27 & -1.35 & .20 & \\
Cubic & .036 & 2.07 & 3 & 165 & .106 & 24.93 & -.93 & .07 & .01 \\
\hline
\end{tabular}

A similar pre-assumed linear regression line was drawn for the relationship between length of residence and social-cultural skills. As shown in Figure 4, there is a trend of increasing social skill levels as students stayed in the United States for a longer period of time. In addition, the smoothened line almost overlaps with the linear line. To take a close statistical look at the data, Table 4 shows the model summary and parameter estimates for both linear and nonlinear regressions. Although both linear and nonlinear models show significant fitness (with FLinear $(1,167)=9.456, \mathrm{p}<.01$; FQuadratic $(2,166)=4.824, \mathrm{p}<.01$; FCubic $(3,165)=3.379, \mathrm{p}<.01)$, the variance explained by the change of model does not change significantly. Therefore, there is a significantly strong relationship between length of residence and social-cultural skill development among international students. Specifically, approximately $54 \%$ of students' enhanced social-cultural skills was due to their longer duration of time spent in the United States. In other words, the 
hypothesized U-curve development of social-cultural skills by length of residence was not supported by the data of the current study. Although the quadratic and the cubic trends were significant, the relationship between the length of residence and the social-cultural skill development, as seen in Figure 1, is not U-shaped but a linear relationship with slow down periods.

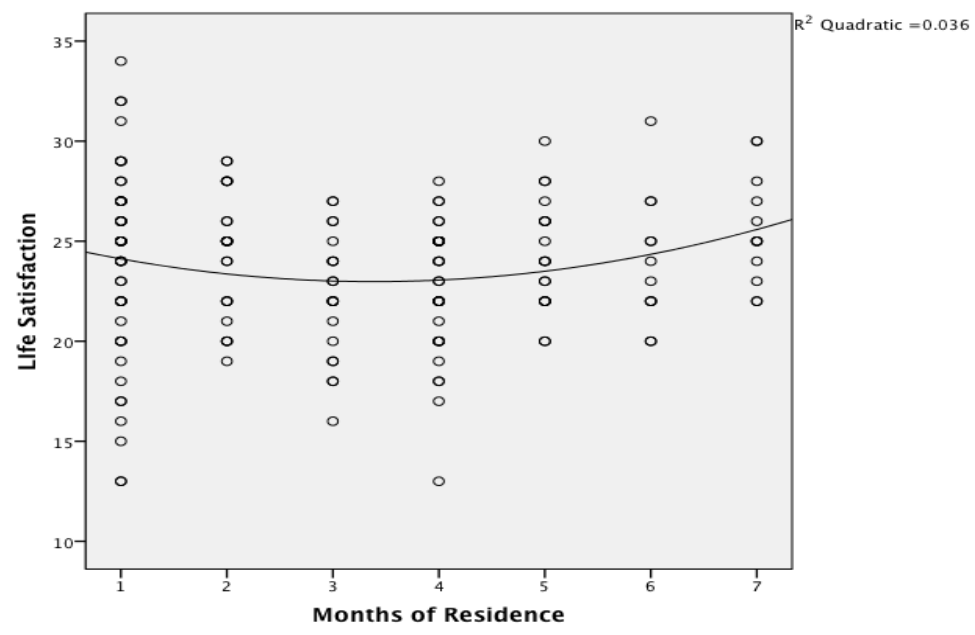

Figure 3. Ucurved

Nonlinear

Estimation of Life

Satisfaction by Length of Residence

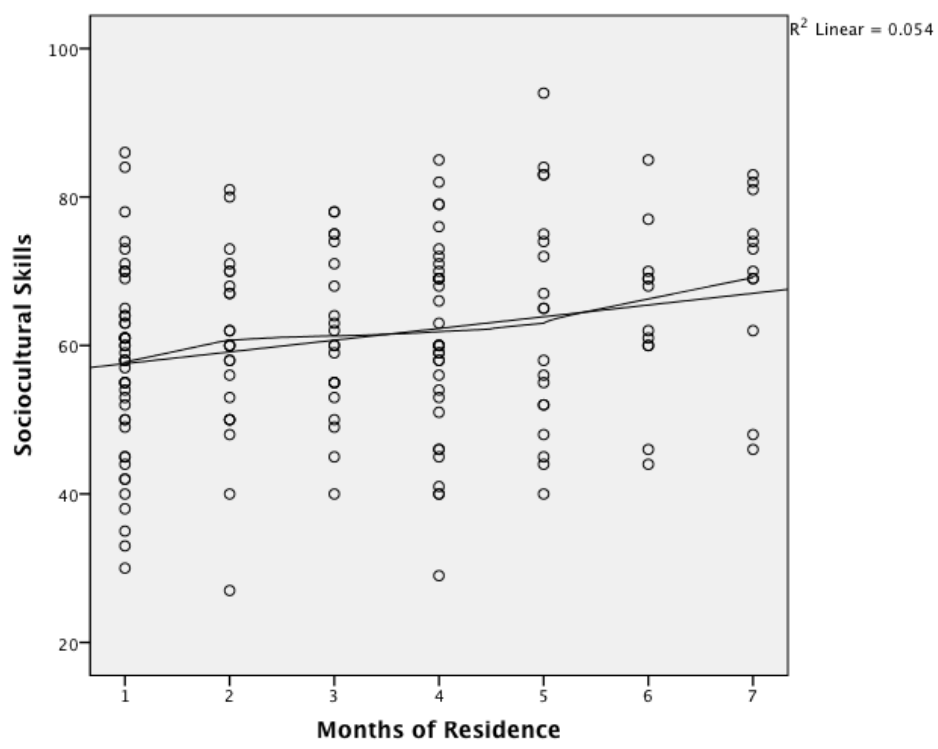

Figure 4.

Examination of Linearity between Length of Residence and Social-cultural Skills 
Table 4. Model Summary and Parameter Estimates for the Regression Relationship between Length of Residence and Social-cultural Skills.

\begin{tabular}{llllllllll}
\hline \multirow{2}{*}{ Equation } & \multicolumn{3}{l}{ Model Summary } & \multicolumn{6}{c}{ Parameter Estimates } \\
\cline { 2 - 9 } & $R^{2}$ & $F$ & $d f$ & $d f$ & Sig. & Constant & $b 1$ & $b 2$ & $b 3$ \\
\hline Linear & .054 & 9.46 & 1 & 167 & .002 & 55.98 & 1.58 & & \\
Quadratic & .055 & 4.82 & 2 & 166 & .009 & 57.26 & .58 & .14 & \\
Cubic & .058 & 3.38 & 3 & 165 & .020 & 53.06 & 5.84 & -1.50 & .14 \\
\hline
\end{tabular}

\section{DISCUSSION AND CONCLUSIONS}

\section{Length of Residence and Life Satisfaction}

The significant differences in two phases of students' life satisfaction partly confirmed the hypothesis that psychological adaptation can be represented by a U-shaped curve of changes over time, in which it goes down to the lowest point after a certain period following one's arrival and then slowly goes up. However, there are two main inconsistencies between the findings of this study and the traditional U-shaped model.

First, there were only two phases of psychological adaptation generated by this research. In contrast, the model proposed by Oberg (1960) defined four phases: Honeymoon, Culture Shock (Crisis), Recovery, and Adjustment. The pattern emerging from this research for the most part follows Oberg's pattern in that students were generally satisfied upon their first period of arrival in an overseas environment. They then suffered from the Crisis period that included unsatisfied and negative feelings. There is a clear downward slope between these two phases in both Oberg's model and the findings of this study. However, the last two phases in Oberg's model, Recovery and Adjustment, were found with no clear boundary in this study. This study found a continuous growth of adaptation during the last two phrases as defined by Oberg. This process is likely to be chronic and smooth. Given the fact that Oberg's model studied cross-cultural experiences without differentiating populations, such as international students, the stages defined in his model may not specifically explain international students' adaptation experiences in some American colleges and universities. The continuous growth of life satisfaction after the twentyfourth month can be interpreted in the context of these students' legal status 
as F1 visa holders. With more institutional efforts in helping these students adjust to the campus environment, it is unlikely for them to have a sudden leap from the recovery phase to the adjustment phase. The two-phase pattern found in this study is actually similar to Markovizky and Samid's (2008) model based on research on immigrants from the former Soviet Union in Israel. These researchers found fewer phases of psychological adaptation for immigrants: Deterioration, Low Well-Being, and Recovery (Markovizky \& Samid, 2008). To a limited extent, this model is supported by the present study.

The second inconsistency lies in the time frame of the different phases of psychological adaptation. Given that the length of residence might impact international students and their lives in various ways, the time at which the crisis of adaptation occurs may vary (Markovizky \& Samid, 2008). In Lysgaard's traditional model (1955), culture shock may appear six to eighteen months after arrival. In other situations, as revealed by Markovizky and Samid's (2008) study of immigrants in Israel, the crisis may appear after a longer period of time - such as the fifth month after arrival. Furthermore, in cases like Selmer's (1999) study, the period of stress and difficulties began as late as the seventeenth or eighteenth month of residency for Western businessmen in Mainland China (Selmer, 1999). In comparison to some of these findings (e.g., Lysgaard, 1955; Markovizsky \& Samid, 2008), international students who took part in this study and whose crisis periods lasted from the ninth month through the twenty-fourth month of residency experienced a delay in entering the toughest period and recovery.

There is little certainty that people in certain groups follow the same temporal pattern, considering individual and contextual variances. However, studying the characteristics of the different statuses of new residents at a group level does help to explain the situation to a certain extent. With respect to international students, there is a delay before the descending slope of the U-curve. This is possibly because most colleges provide supportive programs for first year international students, such as an orientation at the beginning of their study, seminars or regular meetings that address issues concerning professional development, a buddy system, informal gettogethers for students to talk and socialize, and panel discussions in which international students share experiences and problems (Erichsen \& Bolliger, 2011). These support systems could explain why international students may have a smoother transition at the beginning of their stay and a longer 
honeymoon period. During the ninth month of their stay, the first school year of study ends. After this, with less support from the school's programs and heavier academic pressures, it is not surprising that students might start to feel upset and frustrated.

Compared to students, immigrants are exposed sooner to the local community and have immediate concerns, such as employment, savings, and housing (Markovizky \& Samid, 2008). Therefore, they may be confronted with social, economic, and cultural pressures earlier than students. In regards to businesspersons, they probably devote more time to their jobs after arrival and have limited social interactions with the local people (Selmer, 1999), thus resulting in a delay in the onset of culture shock.

Additionally, the delay in recovery revealed in this research is worth noting. In general, recovery occurs at the end of first year of residency. However, in this study, this phase appears after 24 months of residency. Again, there are unique factors associated with international students that may explain this delay. First, considering the geographical features and transportation style of Midwestern America, students may be relatively isolated while attending school, thus having fewer chances to interact with local people. This loneliness and isolation may result in a low level of life satisfaction. Second, academic pressure is another factor to be considered since academic achievement is an important aspect of psychological adaptation, as pointed out by O'Reilly et al. (2010). With increasing levels of class difficulty and workloads, students (especially Asians-who constituted the largest percentage of this research sample) might experience many problems, such as stress, lack of sleep, and some psychosomatic disorders (O'Reilly et al., 2010). These problems could help explain the long-term low levels of psychological adaptation. It seems that international students may have had the clearest understanding at the end of the first school year that it is difficult for them to achieve as expected academically. It is possible they were able to regain their confidence after receiving feedback and earning better grades during the second school year. Together, these reasons align with Lewthwaite's (1996) prior beliefs about international students in New Zealand. Lewthwaite (1996) hypothesized that students were trapped by increasing academic workloads and found it hard to fulfill their desires to interact with people outside of their academic life. Also, considering the age of the students in this study $(M=20)$, their life satisfaction tends to be complicated by emerging adulthood crises, such as 
the uncertainty of a future career and immigration status. Compared with immigrants, some students are slower in adjusting psychologically because of their intention to return to their home country. Many of them keep a very tight network with people from their own country, making it hard to detach themselves from feelings of loss, such as the loss of family (Markovizky \& Samid, 2008).

\section{Length of Residence and Socio-cultural Adaptation}

Contradictory to the U-curve hypothesis, the socio-cultural adaptation of international students in this study grew linearly, and the turning point of two phases of development occurred during the fourth month after arrival. A possible explanation is that the widely used U-curve pattern was generated at a global level of adaptation. There is limited empirical evidence clarifying whether the pattern differs when psychological and socio-cultural adaptation are examined separately. In this sense, when only taking socio-cultural adaptation into account, it seems that skills for international students may develop in a more stable manner without significant retreats, as proposed in the learning curve by Furnham (2010). Previous studies indicate that it is hard to normalize the U-curve proposition. As Ward et al. (1998) found in their research on Japanese students in New Zealand, the toughest time of socio-cultural adaption appeared at entry point and then alleviated as time went on. The results found in this study are consistent and aligned with Ward et al. (1998) regarding the rapid acquisition of socio-cultural skills.

\section{IMPLICATIONS}

Several limitations regarding the research design should be addressed. First, despite the desire to understand a longitudinal phenomenon, the study was cross-sectional in nature. Since time played an important role, it is worth further examining in longitudinal research, in which it is possible to trace every individual's adaptive pathway over time. In addition, a larger and more diverse sample should be obtained in future research. A larger number of participants who are from different colleges in different geographical areas of the United States could make the results more valid, given the differences in physical and social climate across institutions and locales. An additional limitation of the study is that the length of residence was classified into ranges (e.g., 1-4 months, 5-9 months). Future researchers may 
want to consider using more precise and continuous data to obtain more exact estimates of the length of residence (e.g., 1.2 months rather than 1-4 months, or 6.5 months rather than 5-9 months).

In addition to these suggestions for future research, implications for practice also emerge from the findings. Realizing that there can be difficult periods for international students, American colleges and universities could work further on specific programs or interventions to facilitate students' adaptation. According to Erichsen and Bolliger (2011) in their research on understanding international students' isolation in the United States, international students expect more social events and conversational interaction with American students. Consequently, universities should provide ongoing programs and expanded opportunities for international students to interact with Americans (Wilson, 2011). For example, Li et al. (2017) recommend pairing new international students with American student mentors, for at least the first year. They can also arrange events to welcome the students, and can consider pairing each international student with a mentor on campus (Mesidor \& Sly, 2016). Improving university support may also help international students' adjustment. To this end, host universities can maintain a current website with important information on the college, city, and culture to assist international students before and after they arrive (Mesidor \& Sly, 2016).

When planning initiatives and programs for international students, colleges and universities should recognize that adaptation is a process that happens over time. The provided support would be beneficial beyond the first weeks or months on campus. Furthermore, an understanding of the acculturation process would benefit faculty and staff who interact with international students, so that they can have a better understanding of, and be sensitive to, these students' experiences and the challenges they may face.

Although many universities have been providing activities and events for international students, the interactions that these students have may still be limited primarily to other international students. Universities could strive to improve American student involvement in these offerings. Furthermore, research suggests that some international students may expect campus organizations or groups to take initiative in reaching out to them (e.g., Li et al., 2017). Active and personal invitations from these groups to international students might be helpful in making them aware of available resources. In addition, writing classes, English clubs and seminars are 
available in many universities. However, events and programs that improve out-of-class communication in English are also helpful. Finally, universities and colleges could strive to develop community partnership programs to help students build social networks and interact with community members.

\section{REFERENCES}

Berry, J. (1990). Psychology of acculturation. In J. Berman (Ed.), Cross-cultural perspective: Nebraska symposium on motivation (pp. 201-234). Lincoln: University of Nebraska Press.

Berry, J. W. (2005). Acculturation: Living successfully in two cultures. International Journal of Intercultural Relations, 29(6), 697-712.

Bierwiaczonek, K., \& Waldzus, S. (2016). Socio-cultural factors as antecedents of cross-cultural adaptation in expatriates, international students, and migrants: A review. Journal of Cross-Cultural Psychology, 47(6), 767817.

Erichsen, E. A., \& Bolliger, D. U. (2011). Toward understanding international graduate student isolation in traditional and online environments. Educational Technology Research and Development, 59, 309-326.

Brown, L. \& Holloway, I. (2008). The initial stage of the international sojourn: Excitement or culture shock? British Journal of Guidance \& Counseling, 36(1), 33-49.

Diener, E., Emmons, R. A., Larsen, R. J., \& Griffin, S. (1985). The satisfaction with life scale. Journal of Personality Assessment, 49(1), 71-75.

Furnham, A. (2010). Culture shock: Literature review, personal statement and relevance for the South Pacific. Journal of Pacific Rim Psychology, 4(2), 87-94.

Furukawa, T. (1997). Sojourner readjustment: Mental health of international students after one year's foreign sojourn and its psychological correlates. The Journal of Nerves and Mental Disease, 185(4), 263-268.

Gullahorn, J. T., \& Gullahorn, J. E. (1963). An extension of the U-curve hypothesis. Journal of Social Sciences, 19(3), 33-47. doi: 10.1111/j.15404560.1963.tb00447.x

Harrison, G. A. (1993). Human adaptation. New York, NY: Oxford University Press.

Institute of International Education. (2016). International student enrollment trends, 1948/49-2015/16. Open Doors Report on International Educational Exchange. Retrieved from http://www.iie.org/opendoors

Kim, B. S., \& Abreu, J. M. (2001). Acculturation measurement. Handbook of Multicultural Counseling, 2. 
Kim, Y.S., \& Kim, Y.Y. (2016). Ethnic proximity and cross-cultural adaptation: A study of Asian and European students in the United States. Intercultural Communication Studies, 25(3), 61-80.

Kim, Y. Y. (2000). Becoming intercultural: An integrative theory of communication and cross-cultural adaptation. Thousand Oaks, CA: Sage Publications.

Klemens, J. K. \& Bikos, H. B. (2009). Psychological well-being and sociocultural adaptation in college-aged, repatriated, missionary kids. Mental Health, Religion \& Culture, 12(7), 721-733.

Lewthwaite, M. (1996) A study of international students' perspectives on crosscultural adaptation. International Journal for the Advancement of Counseling, 19, 167-185.

Li, Z., Heath, M. A., Jackson, A. P., Allen, G. K., Fischer, L., \& Chan, P. (2017). Acculturation experiences of Chinese international students who attend American universities. Professional Psychology: Research \& Practice, 48(1), 11-21. doi:10.1037/pro0000117

Lysgaard, S. (1955). Adjustment in a foreign society: Norwegian Fulbright grantees visiting the United States. International Social Science Bulletin, 7, 45-51. Retrieved from http://unesdoc.unesco.org/images/0003/000334/ 033411eo.pdf

Markovizky, G., \& Samid, Y. (2008). The process of immigrants' adjustment: The role of time in determining psychological adjustment. Journal of CrossCultural Psychology, 39(6), 782-798.

Mesidor, J.K., \& Sly, K.F. (2016). Factors that contribute to the adjustment of international students. Journal of International Students, 6(1), 262-282.

Moghaddam, F. M., Taylor, D. M. \& Wright, S. C. (1993). Social psychology in cross-cultural perspective. New York, NY: W.H. Freeman.

Oberg, K. (1960). Cultural shock: Adjustment to new cultural environments. Practical Anthropology, 7, 177-182.

O'Reilly, A., Ryan, D., \& Hickey, T. (2010). The psychological well-being and sociocultural adaptation of short-term international students in Ireland. Journal of College Student Development, 51(5), 584-598.

Oropeza, B. A. C., Fitzgibbon, M., \& Baron, A. (1991). Managing mental health crises of foreign college students. Journal of Counseling \& Development, 69, 280-284.

Pavot, W., \& Diener, E. (1993). Review of the satisfaction with life scale. Psychological Assessment, 5(2), 164-172.

Searle, W., \& Ward, C. (1990). The prediction of psychological and sociocultural adjustment during cross-cultural transitions. International Journal of Intercultural Relations, 14(4), 449-464.

Selmer, J. (1999). Culture shock in China? Adjustment pattern of western expatriate business managers. International Business Review, 8, 515-534. 
Tatar, M., \& Horenczyk, G. (2000). Counseling students on the move: The effects of culture of origin and permanence of relocation among international college students. Journal of College Counseling, 3, 49-62.

Trower, P., Bryant, B., \& Argyle, M. (1978). Social skills and mental health. London: Methuen.

Ward, C., Bochner, S. \& Furnham, A. (2001). The psychology of culture shock. Hove, England: Routledge.

Ward, C., Okura, Y., Kennedy, A. \& Kojima, T. (1998). The U-curve on trial: A longitudinal study of psychological and sociocultural adjustment during cross-cultural transition. International Journal of Intercultural Relations, 22(3), 277-291.

Ward, C. \& Searle, W. (1991). The impact of value discrepancies and cultural identity on psychological and sociocultural adjustment of sojourners. International Journal of Intercultural Relations, 15, 209-225.

Wilson, G. P. (2011). Fitting-in: Sociocultural adaptation of international graduate students. NERA Conference Proceedings, 2011, 21.

Wilson, J., \& Ward, C. (2010). Revision and expansion of the sociocultural adaptation scale. Unpublished manuscript.

Yan, K., \& Berliner, D. C. (2009). Chinese international students' academic stressors in the United States. College Student Journal, 43, 939-960

Zeller, W. J., \& Mosier, R. (1993). Culture shock and the first-year experience. Journal of College and University Student Housing, 23. doi: $10.2307 / 2136312$

YIKANG WANG, M.S., completed her Master's degree in Educational Psychology from Miami University in Oxford, Ohio. Email: wangy33@miamioh.edu.

TING LI, Ph,D., completed her doctoral degree in Educational Leadership from Miami University. She is currently is a Curriculum Coordinator and Instructor at the University of Toledo. Email: 1it@miamioh.edu.

AMITY NOLTEMEYER, Ph,D., is professor in Miami University's School Psychology program. Email: anoltemeyer@miamioh.edu.

AIMIN WANG, Ph,D., is professor in the Educational Psychology department at Miami University. Email: wanga@miamioh.edu.

KEVIN SHAW, M.S., is a graduate student in Miami University's School Psychology program. Email: shawkd3@miamioh.edu. 
JINGHUA ZHANG is a doctoral student in the Department of Educational Leadership, College of Education Health and Society, Miami University. Email: zhangj27@miamioh.edu.

Manuscript submitted: March 1, 2017 Manuscript revised: September 8, 2017 Accepted for publication: October 23, 2017 